\title{
HUBUNGAN KUALITAS PERAWATAN KATETER DENGAN KEJADIAN INFEKSI NOSOKOMIAL SALURAN KEMIH DI RUMAH SAKIT UMUM IMELDA PEKERJA INDONESIA MEDAN TAHUN 2019
}

\author{
Christina Magdalena T.Bolon \\ Universitas Imelda Medan, Jl. Bilal No. 52 Kelurahan Pulo Brayan Darat I Kecamatan Medan Timur, \\ Medan - Sumatera Utara. \\ Email:grebyon@gmail.com
}

\begin{abstract}
ABSTRAK
Infeksi nosokomial merupakan kejadian yang sering terjadi di rumah sakit dan dapat menimbulkan kerugian bagi pasien, keluarga dan rumah sakit itu sendiri. Salah satu infeksi nosokomial yang sering terjadi adalah infeksi saluran kemih pada pasien-pasien yang terpasang dower kateter. Faktor-faktor yang menyebabkan infeksi nosokomial saluran kemih antara lain hospes, agent, prosedur pemasangan, lama kateter terpasang dan kualitas perawatan kateter.Tujuan dari penelitian ini adalah untuk mengetahui hubungan kualitas perawatan kateter dengan kejadian infeksi nosokomial saluran kemih.Bentuk metode penelitian ini adalah observasi atau mengamati langsung objek penelitian dan menggunakan instrumen penelitian berupa lembar kusioner.Variable bebas dalam penelitian ini adalah kualitas perawatan kateter dan variable terikatnya adalah kejadian infeksi nosokomial saluran kemih. Yang menjadi subjek penelitian adalah perawat yang memiliki pendidikan diploma tiga dan Strata Satu keperawatan, pasien yang, terpasang dower kateter, diagnosa masuk bukan ISK. Hasil penelitian menunjukan bahwa kualitas perawatan kateter terbanyak adalah cukup (56,7\%), baik (40,0\%) dan kurang (3,3\%). Angka kejadian infeksi nosokomial saluran kemih yang mendapatkan perawatan kateter dengan kualitas cukup sebesar 3.33\% dan, kurang 3,33\%. Perlu adanya peningkatan kualitas perawatan kateter sesuai dengan standar prosedur perawatan dan prosedur pencegahan infeksi dalam proses menekan kejadian infeksi nosokomial saluran kemih akibat pemasangan kateter. Uji statistik menggunakan uji Chi Square untuk menilai hubungan antara kualitas perawatan kateter dengan kejadian infeksi nosokomial saluran kemih. Hasil analisis dengan uji chi square dengan hasil yang di peroleh nilai $P<0,001 \quad(<0,05)$ yang menunjukan ada hubungan kualitas perawatan kateter dengan kejadian infeksi nosokomial saluran kemih.
\end{abstract}

Kata kunci: Kualitas Perawatan Kateter, Infeksi Nosokomial, Saluran Kemih.

\section{ABSTRACT}

Nosocomial infections are events that often occur in hospitals and can cause harm to patients, families and the hospital itself. One of the most common nosocomial infections is urinary tract infections in patients with catheter dower. Factors that cause nosocomial urinary tract infections include host, agent, installation procedure, length of catheter installed and the quality of catheter care. This study aims to determine the relationship between the quality of catheter care with the incidence of urinary nosocomial infection. The method of this study is observation and use of instruments The research is in the form of questionnaire sheets. The independent variable in this study is the quality of catheter care and the dependent variable is the incidence of urinary nosocomial infection. The research subjects are nurses who have DIII and S1 nursing education, patients who are attached with a catheter, the diagnosis is not a UTI. showed that the highest quality catheter care was adequate (56.7\%), good (40.0\%) and lacking (3.3\%). The incidence rate of urinary nosocomial infections receiving catheter treatment with sufficient quality is $3.33 \%$ and, less $3.33 \%$. Statistical tests use the Chi Square test to assess the relationship between the quality of catheter care and the incidence of nosocomial urinary tract infections. The results of the analysis with the chi square test with the results obtained P value $<0.001$ (<0.05) which shows there is a relationship between the quality of catheter care with the incidence of nosocomial urinary tract infections.

Keywords: Quality of Catheter Care, Nosocomial Infection, Urinary Tract.

\section{PENDAHULUAN}

Penyakit infeksi masih merupakan penyebab utama tingginya angka kesakitan, dan kematian di dunia, salah satu jenis infeksi nosokomial. Infeksi nasokomial adalah infeksi yang didapat oleh seorang 
pasien selama dirawat di rumah sakit dengan menunjukan gejala infeksi setelah 72 jam perawatan serta tanda infeksi tidak muncul saat pasien masuk ke rumah sakit. Batasan atau kriteria infeksi nasokomial adalah tanda infeksi tidak muncul saat penderita mulai di rawat tidak dalam massa inkubasi dari infeksi tersebut, tanda infeksi baru muncul minimal $3 \times 24$ jam sejak pasien mulai di rawat dan infeksi tersebut bukan merupakan residual dari infeksi sebelumnya (Hasbull, 1993). Infeksi nosokomial menyebabkan 1,4 juta kematian setiap hari di seluruh dunia (WHO, 2010).

Berdasarkan WHO (2010), Angka kejadian infeksi nosokomial yang di laporkan pada empat region yaitu di eropa, Mediternian Timur, Asia Tenggara, dan Pasik Barat berturut-turut adalah $7,7 \%$, $11,8 \%, 10 \%$, dan $9 \%$ dengan rata-rata kejadian $8,7 \%$. Berdasarkan surveilans yang dillakukan Depkes RI (2009), porposi kejadian infeksi nosokomial di rumah sakit pemerintah lebih tinggi dibandingkan dengan rumah sakit swasta. Penelitian yang dilakukan Marwoto (2010), menujukan bahwa kejadian infeksi nosokomial di limah rumah sakit pendidikan yaitu di RSUP Dr. Sardjito sebesar 7,94\%, RSUD Dr Soetomo sebesar 14\%, RS Bekasi sebesar 5,06, RS Hasan Sadikin Bandun sebesar 4,60\%, RSCM Jakarta sebesar 4,60\%. Angka insiden infeksi nosokomial di Jawa Timur pada tahun 2011 hingga 2013 mengalami tren naik yaitu sebanyak 306 pada tahun 2011, 400 pada tahun 2012, dan 526 pada tahun 2013.

Infeksi nosokomial dapat disebabkan oleh faktor agen (mikroorganisme), hospes (pejamu), dan lingkungan.Infeksi nosokomial dapat terjadi pada penderita, tenaga kesehatan, dan juga setiap orang yang datang ke rumah sakit.Infeksi yang ada dipusat pelayanan kesehatan ini dapat ditularkan atau diperoleh melalui petugas kesehatan, orang sakit, pengunjung yang berstatus karier (Septiari, 2012).

Insidensi ISK secara internasional mencapai $35 \%-45 \%$ dari seluruh infeksi nosokomial (WHO, 2010). Hasil penelitian di beberapa negara Amerika dan Europ melaporkan bahwa kejadian infeksi nasokomial saluran kemih ( urinary tract infection) menempati urutan pertama yaitu sebesar $42 \%$, infeksi daerah operasi sebesar
$24 \%$, dan ventilator associated pneumonia (VAP) sebesar $11 \%$. Berdasarkan laporan National Healthcare Safety Network (NHSN) tahun 2008 menyebutkan bahwa angka kematian akibat infeksi saluran kemih mencapai angka tertinggi yaitu lebih dari 13.000 (2,3\%). Angka insiden infeksi nosokomial di Jawa Timur tahun 2011 hingga 2013 berdasarkan jenis infeksinya pada 13 rumah sakit pemerintah, 2 rumah sakit TNI/Polri dan BUMN dan 14 rumah sakit swasta yaitu infeksi saluran kemih sebanyak 24 kasus. Kebanyakan infeksi saluran kemih yang disebabkan oleh Candida $s p$. Merupakan nosokomial dan terjadi pada pasien yang terpasang kateter urin.Berdasarkan NationalNosocomial Infections Surveillance syste (NNISS), 49\% infeksi nosokomial melibatkansaluran kemih dan Candida albicans merupakan penyebabnya (Aldila, 2011).

Infeksi nosokomial dapat ditularkan melalui cross infection, self infection dan environmental infection. Infeksi nasokomial dapat ditularkan melalui faktor lingkungan yaitu disebabkan oleh mikroorganisme yang berasal dari peralatan di rumah sakit. Infeksi nasokomia saluran kemih $80 \%$ kejadian dihubungkan dengan pemasangan kateter atau yang meliput: lama pemasangan kateter prosedur pemasangan dan perawatan kateter, ukuran dan tipe kateter, serta asupan cairan (putri et al, 2012).

Penyakit infeksi saluran kemih merupakan penyakit infeksi yang banyak ditemukan ditempat pelayanan kesehatan. Angka kunjungan rawat jalan pasien rawat inap yang mengalami infeksi saluran kemih di rumah sakit Amerika Serikat mencapai lebih dari 8 juta pertahun dan menghabiskan biaya USD 500 milyar tiap tahunnya (Hooton, et al.,2010). Kejadian infeksi saluran kemih meningkat seiring dengan penuaan dan ketidakmampuan dalam perawatan diri.Mayoritas infeksi saluran kemih ini didominasi oleh perempuan. (Hooton, et al, 2010 dalam Sepalanita, 2012). Menurut data dari dinas kesehatan provinsi Sulawesi Selatan kejadian ISK pada Rumah Sakit dan Puskesmas perawatan di Provinsi Sulawesi Selatan pada tahun 2008 sebanyak 379 kasus (27\%) pada tahun 2009456 kasus (29\%) dan tahun 2010 sebanyak 346 kasus $27 \%$ (Muhlis, 2012). 
Jumlah pasien rawat inap yang terpasang kateter urin adalah $37 \%$ dari seluruh pasien (Litbang Kementerian Kesehatan RI, 2011). Selain itu didapatkan $38 \%$ kasus infeksi saluran kemih pada pasien yang dipasang kateter disebabkan karena kurangnya perawatan (Furqan, 2013). Kateterisasi yang tidak disertai dengan perawatan yang adekuat menyebabkan berbagai permasalahan khususnya infeksi yang mencapai $28,1 \%$ pasien yang terpasang kateter (Riyadi, 2010).

Kateterisasi urine dilakukan apabila pasien tidak mampu mengeluarkan urine secara normal (retensi dan obstruksi urine). Pemasangan kateter urine menjadi port of entery bagi mikroorganisme untuk masuk ke dalam kandungan kemih pada kateter yang terkontaminasi. Terdapat dua metode yang digunakan dalam kateterisasi uirne yaitu kateter indewelling (kateter menetap) dan kateter intermitten (keteter yang di gunakan sewaktu-waktu).

Kateter tetap akan berpotensi bagi mikroorganisme untuk merkolonisasi ke kandungan kemih melalui 3 hal yaitu: uretra kedalam kandungan kemih pada saat pemasangan kateter, jalur dalam lapisan tipis cairan uretra yang berada di luar kateter, dan migrasi kedalam kandungan kemih di sepanjang lumen internal kateter yang terkontaminasi (Smelzer dan Bare, 2010).

Indikator perawatan kateter (DC) yang berkualitas adalah berdasarkan pengetahuan dan sikap perawatanterhadap standar operasional prosedur (SOP) rumah sakit tentang perawatan kateter (DC). Penelitian yang di lakukan oleh widiya sepalanita (2012) dengan judul pengaruh perawatan kateter urine indewelling model AACN (american association of critical care nurses) terhadap bakteriuria di RSU Raden Mattaher Jambi yang menunjukkan hasil uji bivariat menunjukan bahwa perawatan kateter urin indwelling model AACN signifikan menurunkan bakteriuria dibandingkan kelompok kontrol.

Tinggkat pengetahuan dan pemahaman masing masing perawat berbeda-beda, begitu pula dengan sikap dan perilaku perawat yang tidak sama menjadi salah satu faktor penyebab kualitas perawat kateter (DC). Hasil penelitian yang dilakukan oleh Tri Kesuma Dewi, 2009 tentang tingkat pengetahuan perawat tentang perawatan kateter urin di RS PKU Muhamadiyah Yogyakarta menujukan bahwa tingkat pengetahuan perawat tentang SOP perawatan kateter (DC) secara keseluruhan dalam kriteria baik $20 \%$ dan dalam kriteria cukup sebanyak $80 \%$.

Berdasarkan penelitian yang berkaitan dengan infeksi nosokomial menyatakan bahwa kejadian flebitis yang terjadi karena ukuran katater intravena yang dipasang tidak sesuai dengan ukuran vena pasien sehingga mudah terjadi gesekan ketika pasien bergerak sehingga terjadi peradangan di sekitar area yang terpasang (Herlina \& Jafa, 2018).

Penelitian sebelumnya yang berkaitan dengan infeksi nosokomial saluran kemih menyatakan Penelitian ini diharapkan dapat memberikan informasi mengenai profesionalitas tenaga kesehatan khususnya keperawatan ditunjukkan dari perilaku tenaga kesehatan dalam memberikan pelayanan kesehatan termasuk pelaksanaan program menjaga keamanan pasien (patient safety) berdasarkan standar pelayanan kesehatan, mandiri, bertanggung jawab dan bertanggung gugat, serta mengembangkan kemampuan sesuai dengan perkembangan ilmu pengetahuan dan teknologi (Sagala, 2016).

Penelitian lain yang berkaitan dengan infeksi nosokomial menyatakan kekuatan hubungannya cukup dan hubungan ini bersifat positif yang artinya jika pengetahuan perawat tentang infeksi nosokomial cukup maka makin cukup nilai tindakan pencegahan infeksi yang diperoleh (Damanik, 2018).

Hasil survey awal pada tanggal 22 Maret 2019 yang dilakukan di Rumah Sakit Umum Imelda Pekerja Indonesi didapatkan data pasien di ruangan ICU, HDU 1, HDU 2 yang terpasang kateter sebanyak 20 orang. Hasil wawancara kepada perawat, menunjukkan 5 dari 20 pasien mengalami infeksi nosokomial saluran kemih. Berdasarkan latar belakang yang di atas maka penulis tertarik melakukan penelitian tentang hubungan kualitas perawatan kateter dengan kejadian infeksi nosokomial saluran kemih di RSU IPI MEDAN.

\section{METODE}

Penelitian ini merupakan jenis penelitian kuantitatif dengan desain korelasional. Pendekatan dalam penelitian ini adalah cross sectional yang digunakan untuk mengetahui 
fennomena suatau penelitian dan mengambarkan status atau hubungan fenomena penelitian yang di lakukan dalam satu waktu. Penelitian ini bertujuan untuk menganalisa hubungan antara variabel independen kualitas perawatan kateter dengan variabel dependen yaitu kejadian infeksi nosokomial saluran kemih yang diukur dalam satu kali pengukuran menggunakan kuesioner.

Populasi adalah wilayah generalisasi yang terdiri atas: objek atau subjek yang mempunyai kualitas dan karakteristik tertentu yang di tetapkan oleh peneliti untuk dipelajari dan kemudian ditarik kesimpulan (Sugiono,2009). Populasi dari peneliti ini adalah klien yang terpasang kateter dan perawat di ruangan ICU, HDU 1 dan HDU 2 di Rumah Sakit Umum Imelda Pekerja Indonesia Medan.

Sampel adalah sebagian dari jumlah dan karakteristik yang di miliki oleh populasi.Jumlah sampel yang di pakai dalam penelitian ini adalah 30 orang klien yang terpasang kateter di ruangan ICU, HDU 1, dan HDU 2. Tehnik pengambilan sampel pada penelitian ini menggunakan metode pengambilan sampel total sampling, dimana semua anggota populasi digunakan sebagai sampel (Sugiyono, 2009).

Penelitian ini akan di lakukan di Rumah Sakit Imelda Pekerja Indonesia Medan. Penelitian ini dilakukan pada bulan MaretMei 2019. Waktu penelitian dihitung mulai dari pembuatan proposal sampai penyusunan laporan dan publikasi penelitian.

Tabel 1. Defenisi Operasional

\begin{tabular}{|c|c|c|c|c|c|}
\hline No & Variabel penelitian & Defenisi penelitian & \multicolumn{2}{|c|}{$\begin{array}{l}\text { Alat ukur dan hasil ukur } \\
\text { Kuesioner yang terdiri }\end{array}$} & \multirow{2}{*}{$\begin{array}{l}\text { Skala ukur } \\
\text { Ordinal }\end{array}$} \\
\hline 1 & 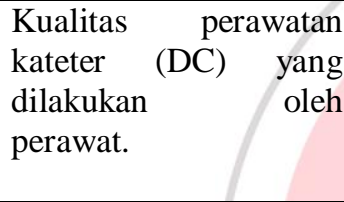 & $\begin{array}{lr}\text { Kesiapan } & \text { atau } \\
\text { kecenderungan } & \text { seseorang } \\
\text { (perawat)untuk } & \text { bertindak } \\
\text { tentang kualitas perawatan } \\
\text { kateter (DC). }\end{array}$ & $\begin{array}{l}\text { Kuesioner yang te } \\
\text { dari } 12 \text { pernyataan } \\
\text { dengan jawaban } \\
\text { Iya dan tidak. }\end{array}$ & diri & \\
\hline 2 & $\begin{array}{l}\text { Kejadian } \\
\text { nosokomial } \\
\text { kemih. }\end{array}$ & $\begin{array}{l}\text { Penyakit yang menujukan } \\
\text { adanya mikroorganisme } \\
\text { dalam urine. }\end{array}$ & $\begin{array}{ll}\text { Data } & \text { rekam } \\
\text { dengan } & \text { Terjadi } \\
\text { Tidak } & \text { Terjadi. }\end{array}$ & $\begin{array}{r}\text { medis } \\
\text { dan }\end{array}$ & Ordinal \\
\hline
\end{tabular}

\section{Cara Pengumpulan Data}

\section{Data Primer}

Data primer dalam penelitian ini diperoleh dengan menggunakan kuesioner yang telah disediakan.

2. Data sekunder

Data sekunder dalam penelitian ini diperoleh dari data rekam medis RSUImelda Pekerja Indonesia Medan.

\section{Data Tersier}

Data yang diperoleh dari jurnal, hasil penelitian orangr lain dari internet yang telah di publikasikan yang berkaitan degan penelitian ini.

\section{Etika Penelitian}

Secara umum prinsip dalam atau pengumpulan data dapat dibedakan menjadi tiga bagian yaitu, manfaat prinsip menghargai hak-hak subjek dan prinsip keadilan (Nursalam, 2010). Data yang didapat dengan cara menekankan etika yang mengacu pada:
1. Informed Consent (Persetujuan)

Informed consent merupakan bentuk persetujuan antara peneliti dengan responden penelitian dengan memberikan lembaran persetujuan. Sebelum dilakukan persetujuan peneliti melakukan penjelasan tentang tujuan, manfaat, prosedur dan harapan penelitian terhadap calon responden. Tujuan informed consent agar subjek mengerti maksut dan tujuan peneliti dan mengetahui dampaknya. Setelah responden memahami semua penjelasan penelitian dan bersedia menjadi responden, selanjutnya responden diminta untuk menandatangani lembar persetujuan sebagai subjek penelitian.

2. Anonamity (Tanpa Nama)

Jaminan dalam pengunaan subjek penelitian dengan cara tidak memberikan nama responden pada lember alat ukur dan kusioner. Kerahasiaan informasi responden yang berkaitan dengan hasil penelitian pada lembar pengumpulan data yang akan disajikan. 
3. Confidentiallity (Kerahasiaan)

Peneliti akan memberikan jaminan kerahasiaan dan tidak akan menceritakan segala hal yang berkaitan dengan hasil yang didapat oleh peneliti baik informasi maupun masalah-masalah lainnya mengenai data pribadi responden. Peneliti, hanya kelompok data tertentu akan di laporkan pada hasil riset jika diminta oleh pihak yang berwenang untuk dapat digunakan seperlunya.

\section{Tehnik Pengolahan Data}

\section{Editing}

Merupakan kegiatan untuk melakukan pengecekkan kelengkapan data yang telah di kumpulkan.

2. Coding

Memberikan kode pada data dengan merubah huruf menjadi angka. Jawabna Ya deberi kode 1 dan Tidak diberi kode 0 , jawaban Setuju diberi kode 1 dan Tidak Setuju 0.

3. Transfering

Memindahkan jawaban atau kode jawaban kedalam media tertentu. Setelah jawaban diberi kode kode tertentu kemudin dipindahkan ke dalam sebuah tabel agar lebuh mudah untuk menghitungnya.

4. Tabulating

Merupakan kegiatan menyusun data dalam tabel. Data disusun dalam sebuah tabel agar lebih mudah dalam menghitungnya.

5. Entry data

Entry data merupakan suatu proses memasukan data kedalam komputer untuk diolah dengan mengunakan SPSS. Sebelum data diklasifikasikan, data dikelompokan terlebih dahulu guna kepentingan penelitian ini, selanjutnya data ditabulasi sehingga diperoleh frekuensi Odari masing-masing kelompok pertanyaan dari setiap alternatif jawabaan yang tersedia. Setelah data dibuat tabel da lam Microsoft Excel, kemudian dipindahkan ke SPSS dan dihitung sesuai dengan rumus.

\section{Analisa Data}

Analisa hasil penelitian ini dilakukan dengan dua cara, yaitu sebagai berikut: a. Analisa univariat

Analisa yang dilakukan mengananilsa tiap variabel dari hasil penelitian. Analisa univariat berfungsi untuk kumpulan data hasil pengukuran sedemikian rupa sehingga kumpulan data tersebut berubah menjadi informasi yang berguna, peringkasan tersebut dapat berupa ukuran statistik. Tabel, grafik. Analisa univariat dilakukan oleh masing-masing variabel yang di teliti (Notoadmodjo, 2005). Pada analisa univariat ini sekaligus bertujuan untuk melihat jumlah responden berdasarkan karakteristik demografi individunya yaitu dilihat dari umur, jenis kelamin, lama bekerja, dan jenis pendidikan. Selain itu juga analisi univariat ini juga untuk melihat sikap perawat tentang perawatan kateter (DC) dan juga kejadian infeksi nosokomial saluran kemih.

b. Analisa Bivariat.

Analisa bivariat yang digunakan adalah statistik chi-square yaitu merupakan analisi untuk mengetahui hubungan semua variabel independent (variabel bebas) terhadap variabel dependent (variabel terikat) yang dapat dilakukan sekaligus, dengan menggunakan uji derajat kemaknaan alpa $=0,05$ (derajat keperjayaan 95\%). Dan bila $\mathrm{p}<0,05$ maka hasil statisktik perhitungan bermakna atau berhubungan.

\section{HASIL}

\section{Hasil Univariat}

Setelah dilakukannya penelitian dengan judul "Hubungan Kualitas Perwatan Kateter Dengan Kejadian Infeksi Nosokomial Saluran Kemih di Rumah Sakit Imelda Medan Tahun 2019" terhadap 30 responden yang diambil dengan cara total sampling maka diperoleh hasil sebagai berikut :

\section{Data Umum}

Tabel 2. Distribusi Karakteristik Responden Berdasarkan Jenis Kelamin Pasien.

\begin{tabular}{cccc}
\hline No & Karakteristik & Frekuensi & $\begin{array}{c}\text { Persentase } \\
\mathbf{\%}\end{array}$ \\
\hline 1 & Laki-Laki & 12 & 40 \\
\hline 2 & Perempuan & 18 & 60 \\
\hline & Jumlah & $\mathbf{3 0}$ & $\mathbf{1 0 0}$ \\
\hline
\end{tabular}

Berdasarkan tabel2 diatas terlihat sedangkan mayoritas responden yang berjenis kelamin perempuan sebanyak 18 
orang $(60 \%)$, minioritas responden yang berjenis kelamin Laki-Laki sebanyak 12 orang (40\%).

Tabel 3. Distribusi Karakteristik Responden Berdasarkan Umur Pasien.

\begin{tabular}{cccc}
\hline No & Karakteristik & Frekuensi & $\begin{array}{c}\text { Persentase } \\
\text { \% }\end{array}$ \\
\hline 1 & $35-40$ & 5 & 16,7 \\
\hline 2 & $41-54$ & 8 & 26,6 \\
\hline 3 & $46-50$ & 9 & 30,0 \\
\hline 4 & $51-55$ & 8 & 26,6 \\
\hline & Jumlah & $\mathbf{3 0}$ & $\mathbf{1 0 0}$ \\
\hline
\end{tabular}

Berdasarkan tabel diatas terlihat bahwa mayoritas responden yang interval usianya 46-50 tahun sebanyak 9 orang (30\%), sedangkan minioritas responden yang interval usianya 35-40 tahun sebanyak 5 orang $(16,7 \%)$.

Table 4. Distribusi Karakteritik Responden Berdasarkan Lama Terpasang Kateter.

\begin{tabular}{cccc}
\hline No & Karakteristik & Frekuensi & Persentase \\
\hline 1 & $<4$ hari & 8 & 26,7 \\
\hline 2 & $>4$ hari & 22 & 73,3 \\
\hline & Jumlah & $\mathbf{3 0}$ & $\mathbf{1 0 0}$ \\
\hline
\end{tabular}

Berdasarkan tabel 4diatas dapat dilihat bahwa bahwa mayoritas pasien yang terpasang kateter selama $>4$ hari sebanyak 22 orang $(73,3 \%)$ sedangkan minoritas pasien yang terpasang kateter selama $<4$ hari sebanyak 8 orang $(26,7 \%)$.

Table 5. Distribusi karakteristik responden berdasarkan Lama Kerja Perawat.

\begin{tabular}{cccc}
\hline No & Karakteristik & Frekuensi & Persentase \% \\
\hline 1 & $2-5$ tahun & 17 & 56,7 \\
\hline 2 & $6-8$ tahun & 13 & 43,3 \\
\hline & Jumlah & $\mathbf{3 0}$ & $\mathbf{1 0 0}$ \\
\hline
\end{tabular}

Berdasarkan tabel 5 diatas dapat dilihat bahwa mayoritas responden berdasarkan lama kerja perawat 2-5 tahun sebanyak 17 orang $(56,7 \%)$, sedangkan minoritas responden berdasarkan lama kerja perawat 68 tahun sebanyak 13 orang $(43,3 \%)$.

Tabel 6. Distribusi karakteristik Responden Berdasarkan Tinggkat Pendidikan Perawat. \begin{tabular}{llll}
\hline No & Karakteristik & Frekuensi Persentase
\end{tabular}

\begin{tabular}{cccc} 
& & & $\mathbf{\%}$ \\
\hline 1 & Diploma & 11 & $36,7 \%$ \\
\hline 2 & Sarjana(S1) & 19 & $63,3 \%$ \\
\hline & Jumlah & $\mathbf{3 0}$ & $\mathbf{1 0 0}$ \\
\hline
\end{tabular}

Berdasarkan tabel 6 diatas dapat dilihat bahwa mayoritas responden tinggkat pendidikan perawat Sarjana (S1) 19 orang (63,3\%), sedangkan minoritas tinggkat pendidikan perawat Diploma 11 orang $(36,7 \%)$.

Tabel 7. Distribusi karakteristik Responden Kualitas Perawatan Kateter yang Dilakukan Perawat.

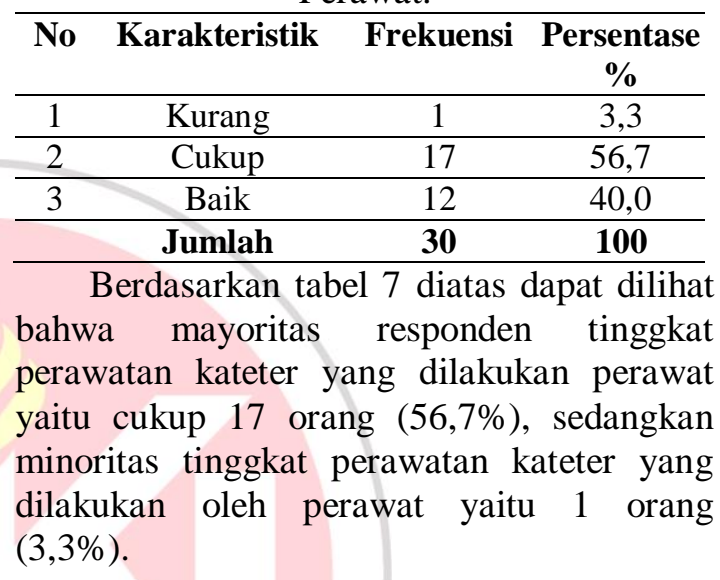

Tabel 8. Distribusi karakteristik Responden Status Pasien yang Terjadi Infeksi Nosokmial Saluran Kemih.

\begin{tabular}{cccc}
\hline No & Karakteristik & Frekuensi & $\begin{array}{c}\text { Persentase } \\
\mathbf{\%}\end{array}$ \\
\hline 1 & Tidak terjadi & 28 & 93,3 \\
\hline 2 & Terjadi & 2 & 6,7 \\
\hline & Jumlah & $\mathbf{3 0}$ & $\mathbf{1 0 0}$ \\
\hline
\end{tabular}

Berdasarkan tabel diatas terlihat bahwa pasien yang terjadi infeksi nosokomial saluran kemih 2 Orang (6,7\%), sedangkan responden yang tidak terjadi sebanyak 28 orang $(93,3 \%)$.

\section{Hasil Bivariat}

Pada penelitian ini data yang diperoleh dapat dianalisa dengan analisis bivariate yaitu untuk mengetahui Hubungan Kualitas Perwatan Kateter Dengan Kejadian Infeksi Nosokomial Saluran Kemih di Rumah Sakit Imelda Medan Tahun 2019. 
Hubungan Kualitas Perawatan Kateter Dengan Kejadian Infeksi Nosokomial Saluran Kemih. berikut:

Berdasarkan analisis bivariat dengan mengunakan uji Chi -Square diperoleh hasil sebagai

Tabel 9. Analisis Bivariat Dengan Mengunakan Uji Chi-Square

\begin{tabular}{|c|c|c|c|c|c|c|}
\hline \multirow{3}{*}{$\begin{array}{l}\text { Kualitas } \\
\text { perawatan } \\
\text { katter }\end{array}$} & \multicolumn{4}{|c|}{ Sataus pasien } & \multirow{3}{*}{ Total } & \multirow[t]{3}{*}{ p hitung } \\
\hline & \multicolumn{2}{|c|}{ Tidak terjadi } & \multicolumn{2}{|c|}{ Terjadi } & & \\
\hline & $\mathbf{N}$ & $\%$ & $\mathbf{N}$ & $\%$ & & \\
\hline Baik & 12 & 40 & 0 & 0 & 12 & \multirow{3}{*}{0,001} \\
\hline Cukup & 16 & 53,3 & 1 & 3,33 & 17 & \\
\hline Kurang & 0 & 0 & 1 & 3,33 & 1 & \\
\hline Total & 28 & 93,3 & 2 & 6,7 & 30 & \\
\hline
\end{tabular}

Ket : Berdasarkan tabel diatas, diketahui pada tinggkat kualitas baik sebesar $40 \%$ dan perawatan kateter yang baik berjumlah 12 (40\%) responden dengan tidak terjadi infeksi nosokomial saluran kemih deengan total 12 , perawatan kateter cukup berjumlah 17 (56,63 $\%$ ) dengan kejadian infeksi saluran kemih 1 $(3,3 \%)$ dengan total 17 dan kurang $0(0 \%)$ dengan kejadian infeksi saluran kemih 1 $(3,33 \%)$ dengan total 1 . Uji chi square yang dilakukan di peroleh nilai $\mathrm{P}<0,001 \quad(<0,05)$ maka H0 ditolak, jadi ada hubungan kualitas perawatan kateter dengan kejadian infeksi nosokonial saluran kemih.

\section{PEMBAHASAN}

Pembahasan dalam penelitian ini dilakukan pada pembahasan tentang Hubungan Kualitas Perawatan Kateter Dengan Kejadian Infeksi Nosokomial Saluran Kemih di Rumah Sakit Umum Imelda Pekerja Indonesia Medan.

\section{Hubungan Kualitas Perawatan Kateter Dengan Kejadian Infeksi Nosokomial Saluaran Kemih}

Hasil penelitian didapatkan perbandingan terhadap hubungan antara perbedaan kualitas perawatan kateter dengan angka kejadian infeksi nosokomial saluran kemih.Kualitas perawatan yang baik angka kejadian infeksi tidak ada yaitu 12 responden (40\%), 12 responden tidak terjadi infeksi. Kualitas perawatan kateter yang cukup sebanyak 17 responden $(56,63), 16$ responden tidak terjadi dan 1 responden yang terjadi infeksi. Kualitas perawatan kateter yang kurang yaitu 1 responden $(3,33 \%), 1$ responden yang terjadi infeksi. Secara keseluruhan prosentase kejadian infeksi nosokomial saluran kemih pada tinggkat kualitas perawatan kurang 3,3\%, dan cukup $3,3 \%$ dari 30 responden. Prosentase tidak terjadi infeksi nosokomial saluran kemih cukup sebesar 53,3\% dari 30 responden.

Presentase kejadian infeksi nosokomial saluran kemih pada responden yang terpasang kateter dan dilakukan perawatan yang kurang, lebih besar di banding dengan responden yang dilakukan perawatan kateter dengan kualitas yang cukup dan baik.

Pada tingkat kulitas perawatan kateter yang baik (40\%) tidak terdapat kejadian infeksi nosokomial saluran kemih dikarenakan dengan kualitas perawatan yang baik dapat mengurangi kejadian infeksi nosokomial saluran kemih.Tapi tidak memungkinkan dengan kualitas perawatan kateter yang baik dapat terjadi infeksi nosokomial saluran kemih, yang disebabkan faktor-faktor lain yang mempengaruhi kejadinan infeksi saluran kemih seperti prosedur pemasangan yang tidak memperhatikan tehnik aseptik dan terlalu lama kateter terpasang.

Pada tingkat kualitas perawatan kateter yang cukup $(53,3 \%)$, masih terdapat terjadi infeksi dibanding kualitas perawatan kateter yang baik. Hal ini mungkin disebabkan ada prosedur perawatan kateter yang tidak di lakukan secara benar misalnya cuci tangan yang tidak sesuai sehingga menjadi media pemidahan organismen.Selain itu juga lingkungan sekitar yang banyak mengandung mikroorganisme, sehingga setiap saat mikroorganisme dapat masuk kedalam tubuh.

Pada kualitas perawatan kateter yang kurang $(3.3 \%)$ angka kejadian sangat besar. Hal ini mungkin terjadi karena adanya pemindahan faktor resiko tinggi yang mengakibatkan kejadian kejadian infeksi nososkomial saluran kemih seperti hospes yang sudah menjelan lansia sehingga sudah terjadi penurunan daya imun sehingga mudah terjadi infeksi. 
Hubungan kualitas perawatan kateter dengan kejadian infeksi nosokomial saluran kemih diperoleh dengan menggunakan uji chi square dengan hasil yang di peroleh nilai $\mathrm{P}<0,001 \quad(<0,05)$. Hasil tersebut dapat disimpulkan bahwa hipotesis 0 (Ho) ditolak dan hipotesis alternatif (Ha) diterima, yaitu ada hubungan kualitas perawatan kateter dengan kejadian infeksi nosokomial saluran kemih.

\section{KESIMPULAN}

Berdasrakan hasil analisis dan pembahasan, maka dapat ditarik kesimpulan sebagai berikut.

1. Karakter responden berdasarkan :

a. Jenis kelamin adalah dari jumlah responden sebanyak 30 orang didapatkan data bahwa mayoritas responden adalah perempuan yaitu sebanyak 18 responden (60\%).

b. Umur adalah dari 30 orang responden sebagian besar dari responden berusia 46-50 tahun yaitu sebanyak 9 responden $(30,0 \%)$.

c. Lama terpasang adalah dari 30 orang responden diperoleh bahwa mayoritas kateter terpasang $>4$ hari yaitu 22 responden $(73,7 \%)$.

d. Lama kerja adalah dari 30 orang responden didapatka data bahwa sebagian besar responden memiliki massa kerja selama 2-5 tahun yaitu 17 responden $(56,7 \%)$.

e. Tingkat Pendidikan adalah dari 30 responden diperoleh hasil bahwa mayoritas responden memiliki pendidikan S1 keperawatan yaitu 19 responden $(63,3 \%)$.

2. Hubungan kualitas keperawatan dengan kejadian infeksi nosokomial saluran kemih. Hubungan kualitas perawatan kateter dengan kejadian infeksi nosokomial saluran kemih diperoleh dengan menggunakan uji chi square dengan hasil yang di peroleh nilai $\mathrm{P}<0,001 \quad(<0,05)$. Hasil tersebut dapat disimpulkan bahwa hipotesis 0 (Ho) ditolak dan hipotesis alternatif (Ha) diterima, yaitu ada hubungan kualitas perawatan kateter dengan kejadian infeksi nosokomial saluran kemih.

\section{DAFTAR PUSTAKA}

A.Aziz, Alimul Hidayat. 2009. Pengantar Konsep Dasar Keperawata. Edisi Pertama, Jakarta : Salemba Medika

Aldila , M. 2011. Pengamatan Lamanya Kateter Urine Terpasang dengan Mulai Timbulnya Kandiduria di RSUD Dr. Kariadi Semarang.

Arya, Dharma dan Sastrodiharjo B. 2009. Faktor Resiko yang Mempengaruhi Terjadinya Infeksi Saluran Kencing Pasca Pemasangan Stent Ureter. Tesis. Denpasar : Universitas Yudayana.

Depertemen Kesehatan Republik Indonesia. 2010, Pedoman Pencegahan dan Penangulangan Infeksi di ICU. Jakarta : Direktorat Jenderal Pelayanan Medik Spesialistik.

Djoyosugito. 2011. Buku Manual Pengendalian Infeksi Nosokomial Di RS. Jakarta : IDI.

Grundemann BJ, Fernsebner B. 2009. Buku Ajarn Keperawatan Prioperatif. Vol. 1. Jakarta. EGC.

Habni, Yulia, 2009. Perilaku Perawatan dalam Pencegahan Infeksi Nosokomial di Ruangan Rindu A, Rindu B, ICU, IGD, Rawat jalan diRSUP $H$ Adan Malik Medan.

Hotoon, T.M,.[et.al]. 2010. Diagnosis, Prevention and Treatmen oa Cather Associated Urinary Tract Infection In Adults: 2009 Internasional Clinical Practice Guidelines from the Infectious Disease Sosiety of America, Guideline s catheter Urinary.

Kumala, S., Raisa, N., Rahayu, L., dan Kiranasari, A. 2009. Uji Kepekaaan Bakteri Yang Diisolasi Dari Urin Penderita Infeksi Saluran Kemih (ISK) Terhadap Beberapa Antibiotika Pada Priode Maret-Juni 2008. Majalah Ilmu Kefarmasian, Vol. V1, No. 2, Agustus 2009,45-55.

Marlina,. Roni, A. S. 2012. Hubungan Pemasangan Kateter Dengan Kejadian Infeksi Saluran Kemih Pada Pasien Diruang Rawat Inap Penyakit Dalam RSUDZA Banda Aceh Tahun 2012. Online (Uilis.Unsyiah.Ac.id.) Diakses Pada Tanggal 26 Januari 2015 Pukul 10.15 .

Muhlis. 2012. Hubungan Antara Pemasangan Kateter Tetap dengaan kejadian infeksi Saluran Kemih Pada 
Pasien Rawat Inap Di RSUD Lapatarai

Kabupaten Barru. (http://Elibrary.stikesnh.ac.id.pdf). Diakses padatanggal 23 januari 2015 pada pukul 19.25

Prabowo, E., dan Pranata, A.E. 2014. Buku Ajar Asuhan Keperawatan Sistem Perkemihan. Nuha Medika : Yogyakarta

Damanik, H. (2018). HUBUNGAN PENGETAHUAN PERAWAT TENTANG INFEKSI NOSOKOMIAL DENGAN TINDAKAN PENCEGAHANNYA PADA PASIEN PASCABE. Jurnal Ilmiah Farmasi Imelda, 4(1), 38-45. http://jurnal.uimedan.ac.id/index.php/JU RNALKEPERAWATAN/article/view/2 $82 / 285$

Herlina, M., \& Jafa, A. G. P. (2018). FaktorFaktor yang Berhubungan dengan Kejadian Phlebitis Pada Pasien yang Terpasang Infus di Rumah Sakit Imelda Pekerja Indonesia (RSU IPI) Medan. Jurnal Ilmiah Keperawatan Imelda Imelda, 4(2), 150-158. http://jurnal.uimedan.ac.id/index.php/JU RNALKEPERAWATAN/article/view/2 98/301

Sagala, deddy S. P. (2016). HUBUNGAN PENGETAHUAN PERAWAT DENGAN
PENCEGAHAN

INFEKSI

NASOKOMIAL DI RUMAH SAKIT UMUM BHAYANGKARA KOTAMADYA TEBING-TINGGI TAHUN 2016. Jurnal Ilmiah Keperawatan Imelda, 2(2), 111-118. http://jurnal.uimedan.ac.id/index.php/JU RNALKEPERAWATAN/article/view/2 $45 / 248$

Septiari, B.B. 2012.Infeksi Nosokomial. Nuha Medika : Yogyakarta

Sofyan, M., dkk. 2014. Perbandingan levofloxacin dengan Ciprofloxacin Peroral dalam Menurunkan Leukosituria sebagai Profilaksis ISK pada Kateterisasi di RSUP. Dr. M. Djamil Padang. (Online). (http://jurnal.fk.unand.ac.id). Diakses pada tanggal 19 maret 2019 pada pukul 21.25 .

Smeltzer S. C.\& Bare B.G (2010) Keperawatan Medikal Bedah(Vols2-3) (Agung Waluyo, penerjemah). Jakarta : EGC.

Suharyanto, T. dan Madjid, A. 2013. Asuhan Keperawatan Pada Klien Dengan Gangguan Sistem Perkemihan. Cv Trans Info Media: Jakarta Timur.

Sukandar, E 2009. Infeksi Saluran Kemih Pasien Dewasa. Sudoyo AW (ed), Buku Ajaran Penyakit Dalam. 